\title{
Accuracy of Ultrasound in the Diagnosis of Acute Appendicitis and Correlation with Histopathology
}

\author{
Shrestha $A^{1}$, Khadka $H^{1}$, Poudel $B^{2}$, Basnet $\mathbf{R}^{3}$, Basnet SB ${ }^{1}$ \\ ${ }^{1}$ Department of Radiology and Imaging, National academy of medical sciences, Kathmandu, \\ Nepal \\ ${ }^{2}$ Department of Surgery, National academy of medical sciences, Kathmandu, Nepal \\ ${ }^{3}$ Department of Pathology, National academy of medical sciences, Kathmandu, Nepal
}

Received: November 10, 2018

Accepted: November 25, 2018

Published: December 30, 2018

Cite this paper:

Shrestha A, Khadka H, Poudel B, Basnet R, Basnet SB. Accuracy of ultrasound in the diagnosis of acute appendicitis and correlation with histopathology. Nepalese Journal of Radiology 2018;8(12):13-19. https://doi. org/10.3126/njr.v8i2.22975

\begin{abstract}
Introduction: Acute appendicitis is a common surgical condition; yet its diagnosis can be elusive at times and missed diagnosis can lead to attendant complications of perforation and its sequelae. On the contrary, negative appendectomy subjects one to unnecessary surgery and its physiological and psychological consequences. Among the various available modalities of diagnosis of appendicitis, Ultrasonography(USG) is easily accessible, non invasive, less time consuming, low cost investigation no radiation hazards. So, USG is appropriate diagnostic modality in our country.

Methods: This prospective observational study was carried out from January 2011 to June 2011 , in the radiology department of Bir hospital. Total of 80 cases with clinical impression of acute appendicitis were enrolled. These patients underwent surgery for suspected acute appendicitis. Details of signs and symptoms, lab findings including Total Leukocyte count (TLC), Differential Leukocyte Count (DLC) and USG findings were recorded. Intra-operative and histopathology findings were also recorded. The findings were analyzed to assess accuracy of ultrasonography in acute appendicitis. Histopathological report was considered the goal standard.
\end{abstract}

Results: A total of 93 cases clinically diagnosed as acute appendicitis were subjected for USG. Out of 93 cases, 80 cases underwent surgery. Among 80 cases, sonography showed acute appendicitis in 56 cases out of which 54 was proved by histopathology as well. However, ultrasonography was not able to detect appendicitis in 9 cases. The sensitivity and specificity of USG for acute appendicitis were $87.7 \%$ and $88.2 \%$ respectively. The positive and negative predictive values were $96.4 \%$ and $62.5 \%$ respectively. Overall negative appendectomy rate of $21.2 \%$ had been used a basis for decision making, the rate of error being $13.7 \%$.

Conclusion: Ultrasonography is a fairly accurate and safe modality in acute appendicitis. It can be useful in reducing negative appendectomy rate.

Key Words: Appendicitis; Appendectomy; Ultrasonography

Correspondence to: Dr. Aimandu Shrestha

Department of Radiology and Imaging

National academy of Medical Sciences

Kathmandu, Nepal

Email:shresthaaimandu@gmail.com

\section{INTRODUCTION}

Acute appendicitis refers to acute inflammation

Cicensed under CC BY 4.0 International License which Licensed under $C C$ permits use, distribution and reproduction in any
pen permits use, distribution and reproduction in an
medium, provided the original work is properly cited 
of the vermiform appendix, which is a blind ended tube arising from the caecum. It is vestigial organ but it can become diseased. Appendicitis is a surgical emergency, and if it is left untreated the appendix may perforate and cause potentially fatal complications especially in children and elderly. The overall mortality rate for acute appendicitis is less than $1 \%$ but is higher in elderly, more than $5 \%$ to $15 \%{ }^{1}$

Despite technological advances, diagnosis of acute appendicitis is still based primarily on history and clinical examination. Prompt diagnosis and surgical referral may reduce the risk of perforation and prevent complications. ${ }^{2}$ Patients with acute appendicitis typically present with central abdominal pain shifting to the right lower quadrant (RLQ) or may present with generalized abdominal pain. Vomiting is common in children. Clinical examination reveals signs of acute intra-abdominal process e.g., local and rebound tenderness, muscle guarding, rigidity, cutaneous hyperaesthesia and tenderness on rectal examination. Since about one third of patients with acute appendicitis present with atypical symptoms. ${ }^{3}$ Differential diagnosis is diverse and includes gastroenteritis, mesenteric lymphadenitis, ovarian and tubal disorder, renal colic, peptic ulcer and acute cholecystitis.

Ultrasonographic criteria of acute appendicitis include blind-ended, non-compressible, aperistaltic tube, with diameter more than 6 $\mathrm{mm}$, arising from the tip of caecum with a gut signature. Visualization of an appendix with an appendicolith, regardless of appendiceal diameter is also regarded as a positive test. However, normal appendix can also be visible on ultrasound. Normal appendix is compressible with wall thickness of less than or equal to $3 \mathrm{~mm}$. The size of appendix can differentiate normal from acutely inflamed appendix. The threshold level for the diameter of the appendix above which acute appendicitis is very likely is $6 \mathrm{~mm} .{ }^{4}$
Routine investigations like total leucocyte count, differential count and plain X-ray abdomen, have been recommended to improve the diagnosis. Plain abdominal radiographs have an overall accuracy of only $8 \% .^{5}$ The routine laboratory examination of blood and urine is mandatory. Leucocytosis is useful but non-specific. It may be absent particularly in very young and old patients. ${ }^{3}$

There has been numerous publications on the use of ultrasound as a diagnostic tool. There studies demonstrate sensitivity of 75\%-94\% and specificity $87 \%-96 \%$. Several prospective studies have been conducted where the result of ultrasonography were used as an aid for surgeons in making an operative decision. Helical CT has reported sensitivity of $90 \%$ $100 \%$, specificity of $91 \%-99 \%$, accuracy of 94\%-98\%, positive predicative value of $92 \%$ $98 \%$, and negative predictive value of $95 \%$ $100 \%$ for the diagnosis of acute appendicitis. ${ }^{6}$, 7,8

This study was conducted to evaluate diagnostic accuracy of ultrasound in acute appendicitis. The study was based on the presumption that an accurate diagnosis helps to reduce high negative appendectomy rates and thereby benefit the patients.

\section{METHODS}

This prospective observational hospital based study was done at Bir hospital, NAMS after obtaining approval from the Institutional Review Board (IRB) from January 2011 to June 2011. Patients more than 15 years of age diagnosed clinically as acute appendicitis were included in the study. Patients in whom ultrasonography could not be performed and those not undergoing surgery were excluded from the study. Patients were subjected for abdominal ultrasonography. USG diagnosis of acute appendicitis was based on the criteria of Jeffery et $\mathrm{al}^{9}$ which includes: 
Non compressible, immobile, blind ended tubular structure with target appearance in transverse view, diameter of visualized structure more than or equal to $6 \mathrm{~mm}$. Supportive features are inflamed perienteric fat, pericaecal collection, appendicolith. ${ }^{9}$ Sonographic findings that met all criteria were diagnosed as positive for appendicitis. All attempts were made to rule out or establish other causes of right lower quadrant pain sonographically.

All the findings including history, clinical examination, laboratory investigation and ultrasound findings were recorded. Intraoperative findings were recorded and histopathologic reports of specimen were noted. The histopathological diagnosis of acute appendicitis would be based on the finding of neutrophilic infiltration of the muscularis propria. The operative diagnosis of acute appendicitis would be based on finding of swollen, shiny /dull, granular redness of appendix judged by attending surgeon.

Results of ultrasonographic impression were compared to clinical impression, intraoperative findings and histopathological reports. Sensitivity, specificity, positive predictive value, negative predictive value and accuracy were computed and comparisons made. Fisher's exact test was utilized to compare USG and intraoperative findings while Chi square test was used to compare USG findings with histopathology.

\section{RESULTS}

A total of 93 cases were clinically diagnosed as acute appendicitis and subjected for USG. Out of 93 cases only 80 cases underwent surgery, 13 cases being excluded from the study. Out of excluded 13 cases, 7 cases were found to have an early appendicular lump on sonography, 2 cases had appendicular abscess, 2 cases had right ureteric calculus and 1 was normal. One case was diagnosed as acute appendicitis sonographically but patient refused surgery.
In these 80 cases, sonography showed acute appendicitis in 56 cases, of which 54 were confirmed by histopathology. One was normal appendix and another Meckel's diverticulum by histopathology. Intra-operatively 53 were acute appendicitis, 2 were normal appendix and 1 was Meckel's diverticulum.b Twenty four cases were normal by sonography, of which 9 were histopathologically diagnosed as acute appendicitis.

Age range of study group was from 16 to 70 years. The mean age was 27.64 years. Standard deviation was 9.6 years. Sixty three cases were histologically acute appendicitis. There were $40(63.5 \%)$ males and 23 (36.5\%) females. Male female ratio was 1.6:1. Sex distribution consisted of $40(63.5 \%)$ male and $23(36.5 \%)$ female. Common age group consisted of 16-25 yrs (47.6\%) and 26-35yrs $(34.9 \%)$. There were no cases in age group 56-65yrs and above 75yrs during the course of this study.

Among 63 cases with histological diagnosis of acute appendicitis, 51 (80.95\%) cases had raised leukocyte counts $(>11,000 / \mathrm{mm} 3)$ and $12(19.05 \%)$ cases had normal leukocyte counts $(4000-11000 / \mathrm{mm} 3)$. Out of 63 cases, $41(65.08 \%)$ cases showed target sign and $22(34.92 \%)$ cases had no target sign. Fifty six patients had an appendix diameter more than $6 \mathrm{~mm}$, two patients had $<6 \mathrm{~mm}$ and in 22 cases appendix could not be visualized. Among those with non- visualization, 9 actually had appendicitis on histopathology. Fifty four caseswith appendiceal diameter $>6 \mathrm{~mm}$ diameter. had acute appendicitis histopathologically

Outof 80 cases which underwent surgeryduring the course of study, sonographic diagnosis of acute appendicitis was made in 56 cases and 24 cases were ruled out as acute appendicitis. Among sonographically diagnosed 56 cases, 53 cases were also diagnosed as acute appendicitis intraoperatively, while 1 case 
diagnosed as Meckel's diverticulum and 2 cases had normal appendix. Among the 24 cases which were sonographically ruled out as acute appendicitis, 15 cases were diagnosed as acute appendicitis and 9 cases as normal appendix intraoperatively. We found ultrasonography has sensitivity of $77.9 \%$, specificity of $75 \%$, positive predictive value of $94.6 \%$, and negative predictive value of $62.5 \%$ and accuracy of $77.5 \%$ in acute appendicitis as compared to intraoperative findings.

Out of 80 cases whichunderwent surgery during the course of study, sonographic diagnosis of acute appendicitis was made in 56 cases and 24 cases were ruled out as acute appendicitis. Among sonographically diagnosed 56 cases, fifty four cases were histopathologically diagnosed as acute appendicitis while 1 case diagnosed as Meckel's diverticulum and 1 case as normal appendix. Among the 24 cases which were sonographically ruled out as acute appendicitis, 9 cases were diagnosed as acute appendicitis and 15 cases as normal appendix histopatholohgically, In our study, ultrasonography has sensitivity of $85.7 \%$, specificity of $88.2 \%$, positive predictive value of $96.4 \%$, negative predictive value of $62.5 \%$ and accuracy of $86.25 \%$ as compared to histopathology findings in acute appendicitis. Out of 80 cases which underwent surgery during the course of study, intraoperative diagnosis of acute appendicitis was made in 68 cases and 12 cases were ruled out as acute appendicitis. Among intraoperatively diagnosed 68 cases, 62 cases were histopathogically diagnosed as acute appendicitis, 1 case diagnosed as Meckel's diverticulum and 5 cases as normal appendix. Among the 12 cases which were surgically ruled out as acute appendicitis 1 case was diagnosed as acute appendicitis and 11 cases as normal appendix histopathogically. We found intraoperative diagnosis has sensitivity of $98.4 \%$, specificity of $64.4 \%$, positive predictive value of $89.7 \%$, negative predictive value of $91.6 \%$ and negative appendectomy of $21.2 \%$ as compared to histopathological findings in acute appendicitis.

\section{DISCUSSION}

In our study out of 80 total cases, 63 cases were acute appendicitis histopathologically, out of them $40(63.5 \%)$ were male and 23 $(36.5 \%)$ were female, male female ratio was 1.6:1 and mean age was 27.64 years. The most common age group was 16-25 years followed by $26-35$ years. In a study by Sigdel et a ${ }^{10}$ done in Kathmandu, mean age was 27.5 years and male to female ratio was 2.6. In most other studies too there is male preponderance. ${ }^{11}$ Our study was supported by Berry et $\mathrm{al}^{5}$. In his study of 246 cases, there was male predominance with $60.2 \%$ male and $39.5 \%$ females. In a study by Khattaket al ${ }^{12}$ out of 663 cases, 447 were male and 216 were female with male female ratio of 2:1. Peak incidence was $2^{\text {nd }}$ and $3^{\text {rd }}$ decade which is also comparable to our study.

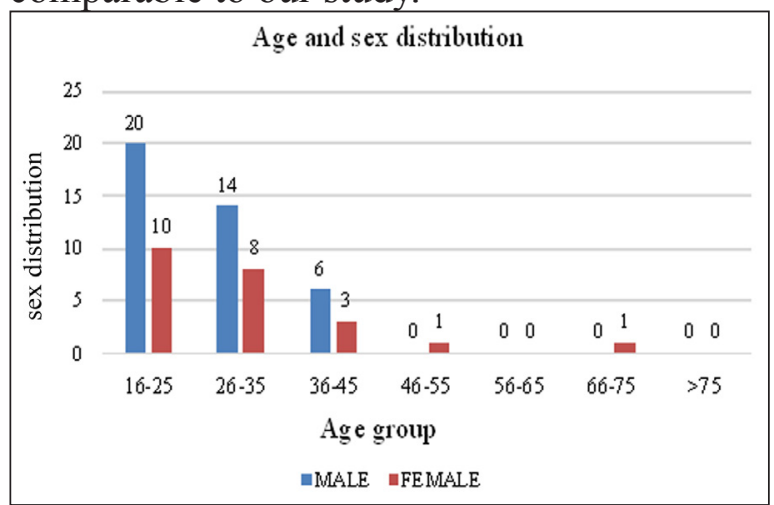

Figure 1: Age and sex distribution

In another study by Omranet $\mathrm{al}^{13}, 58 \%$ of patients were male and age specific incidence of acute appendicitis followed similar pattern for male and female which is also comparable to our study. In our study, increased Leukocyte was found in $80 \%$ cases of histopathologically diagnosed acute appendicitis. However increased leukocytosis is not reliable indicator. Our study was supported by several other studies. ${ }^{14,}{ }^{15,}{ }^{16} \mathrm{In}$ the present study, USG showed a transverse 
diameter of appendix of $\geq 6 \mathrm{~mm}$ in 54 cases, $<6 \mathrm{~mm}$ in 2 cases and appendix was not visible in 22 cases. The visibility of normal appendix on sonography is controversial. Puylaert ${ }^{6}$ in his study concluded that normal appendix is not seen in USG. In contrary to this, studies done by Jeffery et $\mathrm{al}^{17}$ and Rioux ${ }^{18}$ documented the visibility of normal appendix.

\begin{tabular}{|c|c|c|c|c|}
\hline \multicolumn{5}{|c|}{ operative findings } \\
\hline & & \multicolumn{2}{|c|}{ Intra-op } & \multirow{2}{*}{ Total } \\
\hline & & Yes & No & \\
\hline \multirow{2}{*}{$\begin{array}{c}\text { USG } \\
\text { abdomen }\end{array}$} & Yes & 53 & 3 & 56 \\
\hline & No & 15 & 9 & 24 \\
\hline \multicolumn{2}{|c|}{ Total } & 68 & 12 & 80 \\
\hline
\end{tabular}

Transverse diameter $\geq 6 \mathrm{~mm}$ was highly significant in diagnosing acute appendicitis. Our study showed a strong correlation between appendicular transverse diameter of $\geq 6 \mathrm{~mm}$ on USG and histopathology $(\mathrm{P}<0.001)$. The sensitivity and specificity using transverse diameter as a criteria for diagnosing acute appendicitis in present study was $85.7 \%$ and $88.2 \%$ respectively. Study done by Kesller et a ${ }^{19}$ also concluded that threshold diameter of $6 \mathrm{~mm}$ is the most accurate USG finding for appendicitis.

In our study, USG diagnosis, when compared to histopathology, had an accuracy of $86.25 \%$. Ultrasonography correctly identified 54 cases with appendicitis while it also identified 15 cases who had no appendicitis. However there were 9 false negative cases and 2 false positive cases. Had USG been used as a basis for decision making, 9 cases that actually had appendicitis would have been missed. However of these 9 cases, in 7 patients initial clinical diagnosis was also non-confirmatory; they had been conservatively managed initially and decision to operate was taken after 24 hours in view of changed clinical picture.
Table 2: Correlation of ultrasound with histopathology

\begin{tabular}{|l|l|l|l|l|}
\multicolumn{2}{c|}{} & \multicolumn{2}{c|}{ HPE } & \multirow{2}{*}{ Total } \\
\cline { 3 - 5 } \multicolumn{2}{c|}{} & Yes & No & \\
\hline \multirow{2}{*}{$\begin{array}{l}\text { USG } \\
\text { abdomen }\end{array}$} & Yes & 54 & 2 & 56 \\
\cline { 2 - 5 } & No & 9 & 15 & 24 \\
\hline \multicolumn{2}{|l|l|}{} & 63 & 17 & 80 \\
\hline
\end{tabular}

In our study, negative appendectomy rate was $21.2 \%$, i.e. an accuracy of $78.8 \%$. Compared to our USG diagnosis had a higher accuracy at $86.25 \%$. Thus it appears USG may help in reducing negative appendectomy rates. The accuracy in our study was higher than Mohammad et $\mathrm{al}^{20}$. Rioux ${ }^{18}$ and Karstrupet $\mathrm{al}^{21}$ had similar accuracy; $86 \%$ and $86.9 \%$ respectively. Meanwhile $\mathrm{Abu}$ et $\mathrm{al}^{22}$ had higher accuracy than our study.

In our study USG had sensitivity of $85.7 \%$ and specificity of $88.2 \%$. Thus USG was found to be more specific than sensitive. Karstrupet $\mathrm{al}^{21}$, Rioux ${ }^{18}$ and Masek et $\mathrm{al}^{24}$ have reported higher sensitivities while Fung el $\mathrm{at}^{23}$, Horton et $\mathrm{al}^{25}$ and Mohammed et $\mathrm{al}^{20}$ had lower sensitivity levels. Similarly, our specificity rate was comparable to that by Fung et $\mathrm{al}^{23}$. It was lower than that reported by Abu-Yousef et $\mathrm{al}^{22}$, Rioux ${ }^{18}$ and Masek et $\mathrm{al}^{24}$. Karstrup et $\mathrm{al}^{21}$ and Mohammad et $\mathrm{al}^{20}$ had lower specificity levels. The PPV of USG in our study was $96.4 \%$ and NPV was $62.5 \%$. Abu et $\mathrm{al}^{23}$ had lower PPV but higher NPV than ours. Rioux et $\mathrm{a}^{18}$ and Fung et $\mathrm{l}^{23}$ obtained similar results. Mohammad et $\mathrm{al}^{20}$ had both lower PPV and NPV values compared to our study.

There are certain limitations to our study. Firstly the sample size is small and we have not included pediatric population. Secondly, ultrasonography findings vary when the same patient is examined at different points in time or by different clinician, i.e. inter observer variation may be present. So the findings, and consequently the diagnostic accuracy may improve when a review scan is done, especially 
in those cases that present very early.

\section{CONCLUSION}

The sensitivity and specificity of USG in our study was comparable to most other studies; it was more specific than sensitive; thus USG can be more useful to help to confirm the diagnosis of appendicitis rather than ruling it out, i.e. a normal USG cannot rule out appendicitis.

\section{CONFLICT OF INTEREST}

None

\section{SOURCES OF FUNDING}

None

\section{REFERENCES}

1. Fitz RH. Perforating inflammation of the vermiform appendix: with special reference to its early diagnosis and treatment. Am JMed Sci 1886;92:321-346. Available from: http://resource.nlm.nih. gov/65711100R [Accessed 20th Dec $2018]$.

2. Wilcox R.T. Traverso LW. Have the evaluation and treatment of the acute appendicitischangedwithnewtechnology? Surg Clin North Am 1997;77(6):1355-1370 https://doi.org/10.1016/S00396109(05)70622-8

3. Lewis FR, Holcroft JW, Boey J, Dunphy JE. Appendicitis: A critical review of diagnosis and treatment in 1000 cases. Arch surg 1975; 110(5):677-684. https://doi.org/10.1001/ archsurg.1975.01360110223039

4. Wilson SR. The Gastrointestinal Tract. In: Rumack CM, Wilson SR, Charboneam JW, Levine D, editors. Diagnostic Ultrasound. 3rd ed. China: Elsevier Mosby; 2005.p.295.

5. Berry J, Malt RA. Appendicitis near its centenary. Ann Surg 1984;200(5):567-575. https://doi.org/10.1097/00000658-
198411000-00002

6. Puylaert JB. Acute appendicitis: US evaluation using graded compression. Radiology 1986;158(2):355-360. https://doi.org/10.1148/ radiology.158.2.2934762

7. Larson JM, Pierce JC, Ellinger DM et al. The validity and utility of sonography in the diagnosis of acute appendicitis in the community setting. Am J Radiol 153;(4):687-91.

8. Buchman TG, Zuidema GD. Reasons for delay of the diagnosis of acute appendicitis. SurgGynecolObstet 1984;158(3):260-266. Available from: https://www.ncbi.nlm. nih.gov/pubmed/6701739 [Accessed 20th Dec 2018]

9. Jeffery RB, Liang FC, Townsend RR. Acute appendicitis: Sonographic criteria based on 250 cases. Radiology 1988;167(2):327-329.

https://doi .org/10.1148/ radiology.167.2.3282253

10. Sigdel GS, Lakhey PJ, Mishra PR. Tzanakis score vs. Alvarado score in acute appendicitis. $J$ Nepal Med Assoc 2010;49(178):96-99. https://doi.org/10.31729/jnma.105

11. Addiss DG, Shaffer N, Fowler BS. The epidemiology of appendicitis and appendectomy in the United States. Am J Epidemiol 1990;132(5):910-925. https://doi.org/10.1093/oxfordjournals. aje.a115734

12. Khattak S, Aslam S, Kamal A. Acute appendicitis: an audit of 663 cases. Gomal Journal of Medical Sciences 2010;8(2):209-211. Available from: http://citeseerx.ist.psu. edu/viewdoc/download?doi=10.1.1.102 $0.9797 \&$ rep $=$ rep $1 \&$ type $=$ pdf $\quad$ [Accessed 20th Dec 2018].

13. Omran MA, Mamdani MM, Mcleod RS. Epidemiologic features of acute appendicitis in Ontario, Canada. Can J Surg 2003;46(4):263-265. Available from: https://www.ncbi.nlm. 
nih.gov/pmc/articles/PMC3211626/\# [Accessed 20th Dec 2018].

14. Coleman C, Thompson JE, Bennion RS, Schmit PJ. White blood cell count is a poor predictor of severity of disease in the diagnosis of appendicitis. Am Surg 1998;64(10):983-985. Available from: https://search. proquest.com/openview/fad2e $8 \mathrm{dc} 7$ 5a555f26d58f37386a43169/1?pqorigsite $=$ gscholar\&cbl $=49079$ [Accessed 20th Dec 2018].

15. Tehrani HY, Petros JG, Kumar RR, Chu Q. Markers of severe appendicitis. Am Surg 1999;65(5):453-455. Available from: https://search. proquest.com/openview/38c1b4c0 3a98ef1a1427159b188756e6/1?pqorigsite $=$ gscholar \&cbl $=49079$ [Accessed 20th Dec 2018].

16. Thompson MM, Underwood MJ, Dookeran KA, Llyod DM, Bell PRF. Role of sequential leucocyte counts and C-reactive protein measurements in acute appendicitis.BrJSurg 1992;79(8):822-824. https://doi.org/10.1002/bjs.1800790839

17. Jeffrey RB, Laing FC, Lewis FR. Acute appendicitis: High resolution real time US findings. Radiology 1987;163(1):11-14. https:// doi.org/10.1148/ radiology.163.1.3547490

18. Rioux M. Sonographic detection of the normal and abnormal appendix. Am J Radiol 1992;158(4):773-778. https://doi.org/10.2214/ajr.158.4.1546592

19. Kessler N, Cyteval C, Gallix Bet al. Appendicitis : evaluation of sensitivity , specificity, and predictive values of US , Doppler US , and laboratory findings. Radiology 2004;230(2):472-478. https://doi.org/10.1148/ radiol.2302021520

20. Mohammad MAA, Mufti TS, Khattak IU, Chilkunda N, Alshayeb AA, Mohammad AM. Role of ultrasound in acute appendicitis. $J$ Ayub Med Coll Abbottabad 2007;19(3):72-79. Available from: http://ayubmed.edu.pk/
JAMC/PAST/19-3/17\%20Akbar.pdf [Accessed 20th Dec 2018].

21. Karstrup S, Pederson TS, Roikjaer O. Ultrasonic visualization of the inflamed appendix. $\mathrm{Br} J$ Radiol 1986;59(706):985-986. https://doi.org/10.1259/0007-1285-59706-985

22. Abu-Yousef MM, Bleicher JJ, Maher JW, Urdaneta LF, Franken EA, Metcalf AM. High resolution sonography of acute appendicitis. Am J Roentgenol 1987;149(1):53-58. https://doi.org/10.2214/ajr.149.1.53

23. Fung HS, Lau S, Siu JCW, Chan CM, Chan SCH. Audit of ultrasonography for diagnosis of acute appendicitis: a retrospective study. $J$ HK Coll Radiol 2008;11:108-111. Available from: http://docshare01. docshare.tips/files/9742/97429165.pdf [Accessed 20th Dec 2018].

24. Masek T, Poulova M, Schwarz J, Bavor P. Ultrasonography as an auxiliary method in diagnosis of acute appendicitis. Rozhl Chir 2003;82(6):320-323. Available from: https:/www.ncbi.nlm. nih.gov/pubmed/12898783 [Accessed 20th Dec 2018].

25. Horton MD, Counter SF, Florence MG, Hart MJ. A prospective trial of computed tomography and ultrasonography for diagnosing appendicitis in the atypical patient. The American journal of surgery 2000;179(5):379-381. https://doi.org/10.1016/S00029610(00)00372-X 